\title{
AVALIAÇÃO DA FORMAÇÃO EM ENGENHARIA QUÍMICA PELA PERCEPÇÃO DE EGRESSOS DA UFTM (2014-2019) \\ http://dx.doi.org/10.5902/2318133844235
}

\author{
Thais Gama Furini ${ }^{1}$ \\ Vinícius Henrique Vivas ${ }^{2}$ \\ Beatriz Gaydeczka ${ }^{3}$ \\ Priscila Pereira Silva ${ }^{4}$
}

\begin{abstract}
Resumo
Neste artigo apresenta-se um levantamento pelo qual se objetivou conhecer a avaliação do egresso acerca da formação de graduação em Engenharia Química. Foi aplicado um instrumento com questões abertas e fechadas, com a participação de 91 egressos de Engenharia Química da Universidade Federal do Triângulo Mineiro - UFTM - de 2014 a 2019. Destacaram-se como resultados: identificação de aspectos potenciais e fragilidades na formação de egressos que trabalham ou não na área de engenharia química; grande parte dos egressos considera-se satisfeita com a formação, mas evidenciou necessidade de maior ligação teoria/prática e vivência de mercado de trabalho; necessidade de investimentos na formação didático-pedagógica do docente, em inovações tecnológicas para o curso e na maior relação entre o mercado com a universidade.
\end{abstract}

Palavras-chave: egressos; educação em engenharia; avaliação; gestão educacional.

\section{EVALUATION OF TRAINING IN CHEMICAL ENGINEERING BY PERCEPTION OF UFTM EGRESSES (2014-2019)}

\begin{abstract}
This paper presents a survey that aimed to know the evaluation of the egressed student about the formation in the Chemical Engineering. An instrument with open and closed questions was applied, with the participation of 91 students of Chemical Engineering from the Federal University of Triângulo Mineiro - UFTM - (2014-2019). In summary, the following stood out as results: identification of potential aspects and weaknesses in the formation of graduates who work or not in the area of chemical engineering; most of the graduates considered themselves satisfied with the training, but evidenced the need for a greater theory / practice connection and experience of the labor market; the need for investments in the didactic-pedagogical training of the teacher, in technological innovations for the course and in the greater relationship between the market and the university.

Key-words: graduates; engineering education; evaluation; educational management.
\end{abstract}

\footnotetext{
1 Universidade Federal do Triângulo Mineiro, Brasil. E-mail: thais gf@live.com.

2 Universidade Federal de Minas Gerais, Brasil. E-mail: viniciusvivas@yahoo.com.br.

3 Universidade Federal do Triângulo Mineiro, Brasil. E-mail: beatriz.gaydeczka@uftm.edu.br.

4 Universidade Federal do Triângulo Mineiro, Brasil. E-mail: priscila.silva@uftm.edu.br.
}

\begin{tabular}{l|l|l|l|l} 
Regae: Rev. Gest. Aval. Educ. & Santa Maria & v. 9 & n. 18 & Pub. contínua 2020
\end{tabular} 


\section{Introdução}

cenário mundial ditado pela revolução tecnológica tem afetado a relação do mercado profissional e industrial, exigindo das instituições de ensino superior ênfase em sua função educacional, ou seja, foco na aprendizagem dos discentes, preparando-os de forma ampla para desafios cada vez mais complexos, para enfrentar as demandas do mercado e da sociedade (Angelo; Dianesi, 2019; Serafim, 2019). Contudo, o ensino em Engenharia continua formando profissionais com currículos rígidos com distanciamento cada vez mais profundo entre as disciplinas cursadas e as necessidades da sociedade.

Assim, para que as instituições de ensino superior possam acompanhar as mudanças que ocorrem na sociedade e nas indústrias são necessários esforços e investimentos na área de ensino em Engenharia, a fim de que sejam implementadas transformações potenciais nas metodologias de ensino (Oliveira; Pinto, 2006). Os estudos sobre ensino em Engenharia têm se mostrado importantes para que as IES acompanhem as transformações da indústria. Existe a necessidade de se desenvolverem estratégias para que fragilidades de aprendizagem sejam sanadas. É fundamental a busca contínua por avanços na educação em engenharia, em um mercado de trabalho onde não se é mais possível obter os resultados esperados realizando o mesmo tipo de ensino que se deu nas primeiras escolas de Engenharia (Oliveira et al., 2013).

Observou-se que após a revogação, em 1997, da resolução 48/76, dos currículos mínimos, houve uma flexibilização na organização curricular dos cursos de Engenharia, buscando um perfil de egresso mais abrangente, não apenas técnico, permitindo a IES determinar as características e especificações necessárias para a formação dos engenheiros, com a preocupação nas habilidades essenciais, sem deixar de ponderar os aspectos humanísticos, sociais e ambientais (Pinto; Portela; Oliveira, 2003), considerando análises em sua totalidade, em sua inserção na cadeia de causas e efeitos de múltiplas dimensões (Angelo; Dianesi, 2019). O parecer do CNE/CES n. 1.362/2001 destacava a necessidade de considerar na formação experiências em atividades tais como iniciação científica e tecnológica, programas de educação tutorial, programas e projetos de extensão, visitas técnicas, eventos científicos dentre outros.

Nesse contexto, a avaliação dos egressos quanto aos impactos das tentativas de inserção no mercado de trabalho ganha importância e destaque. De acordo com Lousada e Martins (2005) é indispensável saber o que o egresso pensa da formação recebida e sua posição no mercado de trabalho, para que a IES entenda qual o tipo de profissional está formando para a sociedade.

Para Vasconcelos (2012) deve existir um meio para que o ponto de vista dos egressos seja considerado, para que sua percepção sobre a educação oferecida pela universidade seja concebida, avaliada e, a partir disso, reconhecidas as fragilidades e as potencialidades. Assim, é necessário que a avaliação com os egressos ocorra de forma regular e que seja institucionalizada, buscando a melhoria contínua do curso. Assim, busca-se a partir dessas percepções encontrar aplicações a indicadores de qualidade para que se tomem medidas imediatas, de médio e de longo prazo.

Além disso, a interação sistematizada entre a IES e seus egressos deve ser utilizada como um indicador de qualidade, sendo adotado como um apontamento da realidade da IES. De modo geral as instituições não priorizam o debate sobre o perfil do egresso. As 
definições são genéricas, confusas e trazem pouca novidade. O novo instrumento com indicadores de avaliação do Inep valoriza e induz as IES a repensarem o perfil do egresso. Da mesma forma induz o vínculo com os empregadores. A IES que desenvolver projetos que respondam aos diferentes problemas da sociedade será beneficiada na avaliação, já que criará vínculos com a sociedade (Reis; Covac; Covac, 2018).

Nesse sentido, este trabalho teve como objetivo realizar um levantamento de dados sobre o impacto do curso de Engenharia Química da UFTM, especialmente na vida profissional dos egressos, possibilitando compreender se o currículo da IES atende às necessidades do mercado industrial atual, como os novos profissionais estão exercendo funções na área de formação e como estes avaliam a formação recebida.

\section{Síntese de trabalhos correlatos}

A literatura conta com uma gama de trabalhos relacionados com análises ou metodologias para coleta da percepção dos egressos acerca da qualidade do curso em que se formaram, no entanto, ainda há poucos estudos no âmbito dos cursos de Engenharia.

Faria e Souza Júnior (2007) mostraram propostas de melhoria do projeto pedagógico por meio do acompanhamento dos egressos do curso de Engenharia de Produção da Usiminas em Minas Gerais. Nesse levantamento verificou-se que $71 \%$ dos egressos estavam satisfeitos com o curso que realizaram, $47 \%$ disseram que faltava mais disciplinas práticas no curso. Para $36 \%$ o fator mais importante para contratação dos egressos foi ter uma visão sistêmica, para $21 \%$ foi a experiência prática. A maioria dos participantes entenderam que as habilidades mais exigidas para exercício profissional são trabalhar em equipe e liderança: habilidades que deveriam ser melhor desenvolvida na universidade. Algumas propostas do corpo docente, mediante os resultados da pesquisa, foram: dar maior incentivo a atividades extracurriculares, rever o número/ementa das aulas práticas a fim de uma maior interação teoria e prática, trabalhar com estudos de caso por meio de artigos técnicos e propor problemas para serem resolvidos pelos alunos.

Mello et al. (2011) analisaram a relação entre as expectativas dos estudantes e a realidade do mercado de trabalho por meio da visão dos graduados e dos egressos de Engenharia Química na Universidade Federal de Santa Maria. Para os atuantes na profissão o curso atendeu parcialmente as expectativas. Apenas $21,4 \%$ dos atuantes da profissão trabalhavam na área industrial e contando com 42,9\% atuava em órgão público federal, em instituições de ensino. Pôde-se notar a importância da relação de atividades extracurriculares com a obtenção do emprego ou estágio, que representa $22,8 \%$ para iniciação científica e empresa júnior e estágio extracurricular com 22,2\%. Já para os que não atuavam na área a expectativa na formação profissional subiu para $75 \%$ de completa aprovação, que se relacionavam $50 \%$ acima da média na graduação. Não foram destacados diretamente os motivos pelos quais os egressos não ingressaram no mercado da Engenharia Química, porém, 33,3\% preferiram realizar outro curso de graduação. Os resultados sugeriram que o curso poderia ter uma carga horária mais concentrada para que fosse possível realizar mais atividades extracurriculares, incluindo estágios na região, da mesma forma, sugeriram um curso menos teórico e mais prático. 
Vivas et al. (2018) avaliaram o perfil, a motivação e a satisfação de discentes durante o período em que estavam cursando Engenharia Química da Universidade Federal do Triângulo Mineiro a fim de compreender as necessidades dos estudantes. Os resultados sugeriram que estes apresentavam altos níveis de motivação e bons níveis de satisfação com o curso, sendo os alunos ingressantes mais motivados que os concluintes. Dentre as atividades extracurriculares $41,9 \%$ optava por iniciação científica, $34,9 \%$ por monitoria, 22,1\% por atividades de extensão, como semana acadêmica, empresa júnior e centro acadêmico. De acordo com resultados $43,6 \%$ dos estudantes que afirmaram insatisfeitos com o curso destacaram: o planejamento e o oferecimento anual de disciplinas; quantidade elevada de pré-requisitos; carga horária excessiva; falta de tempo e incentivo para realização de atividades extracurriculares; falta de incentivo para realização de estágio; número baixo de aulas práticas. Pôde-se perceber que muitos destacavam o distanciamento da teoria com a prática industrial, porém, menos de $60 \%$ dos alunos frequentavam eventos, os quais possibilitavam essa aproximação.

Giacomin, Simon e Tosta (2019) analisaram o perfil e as perspectivas dos egressos do curso de Administração da Universidade Federal da Fronteira Sul que contribuíram tanto para analisar o impacto da graduação em sua vida profissional, como os principais aspectos a serem aprimorados no curso e gestão do campus. Foram coletadas as informações dos graduados a partir de formulário online enviado por e-mail e redes sociais. O estudo revelou que a maioria dos ex-alunos participou de atividades extracurriculares, como estágios, projetos de pesquisa, empresa júnior e projetos de extensão, afirmando que estas agregaram melhor qualidade à formação recebida pelos estudantes. Isso os ajudou nas escolhas profissionais e no aprimoramento de aptidões necessárias para mercado de trabalho. Foram avaliados aspectos em relação à componentes do curso, como bibliografia, corpo docente, didática adotada, relação teoria/prática e currículo. Todos os indicadores foram avaliados positivamente. Os resultados demonstraram que apenas pequena parte dos graduados optou por carreira acadêmica, demonstrando assim a necessidade do curso em focar nas habilidades/competências que se ajustam a este fato, além de explorar melhor a relação teoria/prática. Ressaltou-se também a necessidade de melhoria de infraestrutura, melhorias em laboratórios, ampliação de programas de internacionalização, melhorias nos projetos de pesquisa e extensão, incentivo a realização de extracurriculares.

\section{Resultados e discussão}

Com a finalidade de avaliar o curso a partir da visão dos egressos acerca da qualidade da formação em Engenharia Química da UFTM, foi aplicado um instrumento online, alocado na plataforma GoogleForms enviado por e-mail, com 35 questões, abertas e fechadas, abordando o impacto do curso na vida profissional dos egressos. As respostas obtidas com o questionário online foram analisadas e discutidas. $\mathrm{O}$ envio do questionário foi realizado de julho a outubro de 2019, foram obtidas 91 respostas de 161 egressos, no período de 2014 ao primeiro semestre 2019 , compondo $55,9 \%$ do total.

Perfil geral do egresso: no período de realização da pesquisa o curso de Engenharia Química da UFTM possuía, de 2014 até o primeiro semestre de 2019, 161 egressos, sendo $58,3 \%$ mulheres e $41,6 \%$ homens. A maioria dos egressos, $79,1 \%$ se consideram brancos, $19,8 \%$ pardos e apenas $1,1 \%$ pretos, entretanto, o pequeno percentual de 
negros e indígenas se dá ao fato de que a UFTM, através do vestibular como forma de ingresso até o ano de 2013, ainda contemplava um pequeno percentual para cotas. De acordo com Gaia e Gaydeczka (2017, p.19), somente em 2013 foi aprovada a "adesão plena da UFTM ao Sisu como processo de seleção às vagas iniciais dos cursos de graduação e também a adesão direta aos $50 \%$ de vagas destinadas à Lei no 12.711 , de 29/08/2012", aumentando a adesão de outras etnias na universidade. A parcela mais evidente de participantes foi a dos ingressantes de 2013, com 29,3\% de representatividade, seguindo-se de 2010, com 24,2\%. A maioria dos graduados concluiu o curso no ano de 2018. O curso de Engenharia Química da UFTM tem duração de cinco anos e os concluintes formaram em um tempo igual ou maior que cinco anos, sendo o número de entrada maior que de saída, e decorrência da alta taxa de retenção do curso.

Acerca do estado civil $89 \%$ são solteiros e $11 \%$ casados, não havendo nenhum divorciado, viúvo ou separado. Em comparação ao levantamento feito por Vivas et al. (2018) ocorreram alterações significativas no estado civil dos participantes após a graduação. Em 2016, os até então alunos, declaravam-se em quase totalidade como solteiros $(98,3 \%)$. Provavelmente essa mudança na composição familiar pode estar relacionada a independência profissional e financeira após a titulação.

Grande parte se considera financeiramente independente, representados por $58 \%$ dos entrevistados, porém, ainda é amplo o número dos egressos que não se consideram independentes financeiramente, com $42 \%$.

Quanto à cor e raça, 79,3\% dos egressos se autodeclaram brancos, 19,8\% pardos e apenas $1,1 \%$ pretos, entretanto, o pequeno percentual de negros e indígenas se relaciona ao fato de que a UFTM, pelo vestibular como forma de ingresso até o ano de 2013, ainda contemplava um pequeno percentual para cotas.

Em relação ao emprego $30 \%$ exercem atividades relacionadas a Engenharia Química, 23\% estão em programa de pós-graduação, 6,6\% são autônomos e 7,4\% estão desempregados. A porcentagem de egressos desempregados está abaixo da média nacional, segundo o PNAD-Contínuo para o último trimestre de 2019 a taxa geral de desemprego no país foi de $11,8 \%$, sendo que para pessoas com nível superior a porcentagem de desocupação foi de 9,6\% (IBGE, 2019). A maioria, 85\%, estão morando na região Sudeste, $8 \%$ em outras regiões do país, e 7\% encontram-se no exterior. Cerca de $50 \%$ vivem na região de sua cidade de origem e $48 \%$ ainda vivem próximos a Uberaba, cidade de formação. O Triângulo Mineiro e Alto Paranaíba, região onde se encontra Uberaba/MG, apresenta grande diversidade industrial com destaque para 0 agronegócio, indústria de alimentos, fosfato, nióbio, entre outros.

Com o intuito de analisar mais detalhadamente os resultados o instrumento foi organizado em duas partes: a primeira para os formados que exercem atividades na área e a segunda para os que não atuam como engenheiros químicos ou não estão trabalhando na área de Engenharia Química.

Engenheiros químicos que atuam na área de Engenharia Química: foi possível observar que $34,1 \%$ dos egressos estão exercendo atividades na área de Engenharia Química, sendo contabilizados neste percentual os egressos que estão cursando pósgraduação na área, e que $12,9 \%$ são contratados efetivamente como engenheiros químicos. Dentre os atuantes $35,5 \%$ conquistaram seu primeiro emprego na área de formação no ano de 2019. Os fatores que mais influenciaram na conquista do primeiro 
emprego foram as atividades extracurriculares realizadas em período acadêmico e em estágio. A maioria das vagas (55\%) foram adquiridas a partir de Processo Seletivo/CLT ou Pessoa Jurídica, 32\% com contratação pós-estágio na mesma empresa, 10\% por indicações e 3\% por outros meios. Apesar de um notável crescimento do movimento empresarial júnior na UFTM e de eventos internos relacionados ao tema, nota-se que não há relatos de graduados que abriram seu próprio negócio na área de Engenharia Química. Este fato é um indicativo de que ações específicas relacionadas ao empreendedorismo e inovação devem ser intensificadas, inclusive com a adoção do tema em parte das disciplinas como sugere as novas DCNs das engenharias (Brasil, 2019).

Dentre as diversas áreas de atuação do engenheiro químico as que mais se destacaram foram: $42 \%$ processamento industrial; $29 \%$ controle de qualidade na indústria; $16 \%$ área acadêmica; $10 \%$ em pesquisa e desenvolvimento industrial e apenas 3\% para administrativo-financeiro industrial. Analisando a faixa salarial dos egressos nota-se que $38,7 \%$ recebem entre 1 a 3 salários mínimos, decorrente da principalmente alocação em programas de pós-graduação; 35,5\% recebem entre 3,1 a 6 salários mínimos, em que é observada a possibilidade de se chegar ao piso salarial do engenheiro químico que, de acordo com a lei n. 4.950-A/66 de 1966, é de seis vezes o maior salário mínimo comum vigente no país. Aos que recebem de 6,1 a 10 e maior que 10 salários mínimos a porcentagem também é significativa, chegando a $25,8 \%$.

Figura 1 -

Áreas de atuação dos egressos em Engenharia Química da UFTM (2014 - 2019).

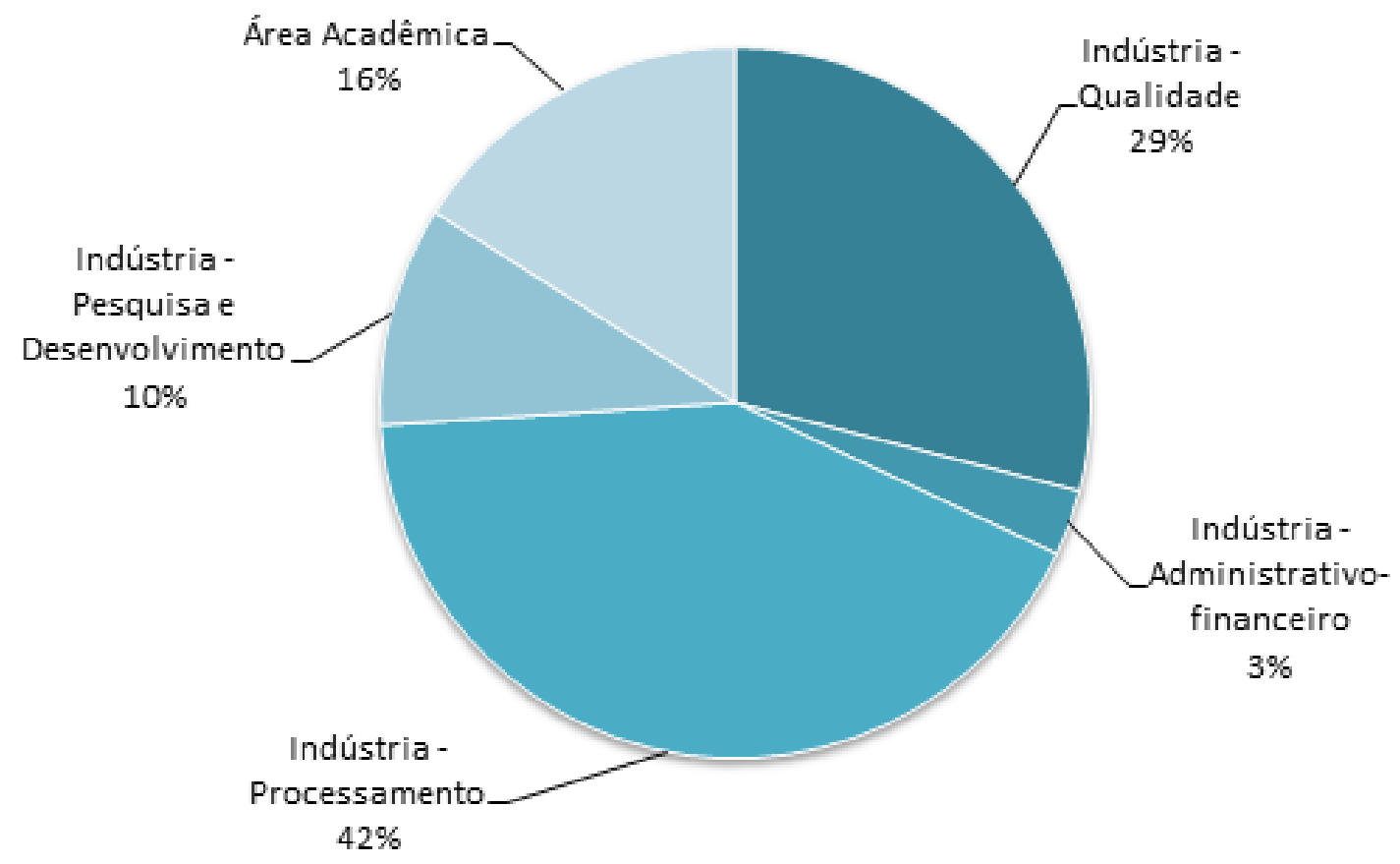

Fonte: autores (2020).

Quando questionados se a formação acadêmica foi adequada ao exercício da profissão $87,1 \%$ responderam que sim. Em grande parte, pode-se notar que os alunos de pós-graduação ficaram muito satisfeitos com a base do curso, juntamente com os profissionais atuantes no mercado. 
A maioria se sente realizada profissionalmente como engenheiro químico $(71 \%)$, mesmo com todas as dificuldades englobadas na atuação da profissão. Já 93,5\% dos participantes afirmaram desejo de continuar trabalhando na área de engenharia química. Entretanto, algumas adversidades foram enfatizadas se destacaram, tal qual lidar com excessiva responsabilidade, baixos salários, muito estresse e lidar com vários tipos de pessoas.

Engenheiros químicos que não atuam na área de Engenharia Química: a atuação dos egressos que estão fora da área Engenharia Química engloba área comercial, vendas, administrativa, financeira, gestão de projetos e tecnologia da informação. Entre os fatores que levaram a não atuar especificamente na área são: a falta de oportunidades, a preferência por seguir carreira acadêmica, a oportunidade em outras áreas e necessidade de empreender.

\section{Potencialidades e fragilidades avaliadas com relação ao curso de Engenharia Química}

A satisfação geral com o curso realizado na UFTM foi alta, $74,7 \%$ dos egressos se sentiram satisfeitos pela formação educacional ofertada pela universidade. A parte teórica do curso foi muito bem avaliada, sendo uma das principais qualidades referenciadas pelos ex-alunos. Porém houve uma elevada demanda por um maior número de aulas práticas, necessidade de ligação da teoria com a prática e vivência de mercado de trabalho por parte dos docentes. Além disso a maioria dos egressos expressou a grande importância na participação em atividades extracurriculares oferecidas pela universidade, mostrandoas como um diferencial, o que demonstra uma demasiada necessidade de incentivo a estas. Dentre as respostas destacam-se:

"As práticas não conseguiam abranger as diversas situações vividas no dia a dia do engenheiro. E a teoria consegue direcionar ao menos uma possível solução, mas com toda certeza as atividades extracurriculares

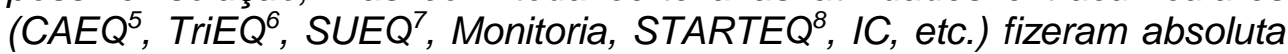
diferença."

"Entendi logo cedo que só faculdade não iria fazer eu me destacar em nada. Logo procurei projetos extracurriculares, e estes foram que construíram minhas habilidades hoje. Infelizmente como o curso aborda muita coisa, um pouquinho de tudo, geralmente o aluno fica bom em nada, vide ENADE. Construí um negócio com base em know how adquirido em organizações de SUEQ's, TRIEQ e afins."

"Pela idade que tem, já é um curso muito bom! Mas senti que faltou um melhor preparo para o mercado de trabalho, coisas práticas que iríamos encontrar após a graduação. Maior incentivo a atividades extracurriculares e apoio em conseguir estágios não obrigatórios de maior duração (não só no último semestre do curso)."

\footnotetext{
${ }^{5}$ Caeq - Centro Acadêmico da Engenharia Química da UFTM.

6 Trieq - Empresa Júnior de Engenharia Química da UFTM.

7 Sueq - Semana Universitária de Engenharia Química da UFTM.

8 Starteq - Evento de empreendedorismo e autoconhecimento para aproximação empresa/universidade da UFTM.

Regae: Rev. Gest. Aval. Educ.

v. 9 ก. 18

Pub. contínua 2020 p. $1-16$
} 
Observa-se demanda por ligação teoria e prática por parte dos egressos que, segundo eles, devido à extensa carga teórica do curso, o aluno fica impossibilitado de realizar mais de um estágio durante o período da graduação, causando dificuldade em inserir-se e adaptar-se ao nível profissional, salvo para os alunos de pós-graduação e os que decidiram seguir carreira acadêmica. Além da constante queixa por parte dos exalunos de que a maioria dos professores não possuem grande experiência no mercado de trabalho, o que acarreta um grande descompasso entre a teoria e prática.

Segundo os participantes as principais áreas técnicas com falhas na formação foram nas áreas de: Fenômenos de Transporte, como $61,5 \%$ dos egressos considerando com falhas técnicas; Materiais da Indústria Química (39,6\%); Balanço de Massa e Energia $(25,3 \%)$ e Termodinâmica $(24,2 \%)$. Dentre os relatos dos egressos, destacam-se:

"Hoje [...] atuando na área de processos eu percebi que um dos fundamentos mais importantes para o engenheiro químico que é "processos" (Fenômenos de Transporte, Operações Unitárias), quase não foi abordado da maneira correta [...]. As aulas práticas não foram convergentes com a realidade do profissional da área."

"Em geral, na área que estou atuando vejo muito processos que vi na faculdade [...] para quem vai seguir carreira na área industrial é essencial um curso mais aprofundado com metodologia de melhorias (não só um semestre como é, $\left.P P C Q^{9}\right)$."

"O curso foi sendo aprimorado ao longo dos anos, em relação a grade, carga horária e estrutura da universidade também melhorou [...]. O que sinto maior defasagem do curso foi na utilização de softwares, como por exemplo o Aspen, estatística. Em relação as disciplinas as de maior defasagem foram: projetos de indústrias, fenômenos de transporte e operações unitárias II."

"Primeiro elogio vai para a área de controle de processos, pois grandes lacunas que foram apresentadas durante o intermédio do curso, foram preenchidas por controle de processos. Operações Unitária I, foi muito fraco, principalmente na área de hidráulica, recomendo chamar um profissional da área (externo) para dar minicursos, que apresente pontos importantes e vivenciais da área. Operações Unitária II, apresentou mais resultados que as outras OP's, no entanto segue o mesmo conselho."

"Professores muito qualificados. [...] Algumas disciplinas como Otimização, Projetos de Instalações foram vistas de forma muito superficial, sem muita contribuição para a formação. Falta levar o aluno mais para dentro da realidade da indústria, mostrando as áreas de atuação e competências exigidas."

O descompasso teoria-prática fica evidenciado em relação a disciplinas do ciclo básico e do âmbito profissional do curso a partir dos comentários dos egressos. Nesse contexto existe a necessidade real de uma reavaliação nas metodologias de ensino aplicadas pelos docentes a fim de diminuir este distanciamento teoria-prática. No caso específico da disciplina de Fenômenos de Transporte esta, segundo os participantes, foi avaliada a com maior índice de falhas na formação dos alunos. Essa percepção é de

9 PPCQ - Planejamento da Produção e Controle de Qualidade, disciplina do curso de Engenharia Química da UFTM.

Regae: Rev. Gest. Aval. Educ.

v. 9

ก. 18

Pub. contínua 2020

p. $1-16$ 
grande relevância por considerarmos a disciplina como um dos pilares na formação do Engenheiro Químico. Assim, este resultado é um indicativo de que medidas de intervenção pedagógicas como reavaliação do formato da disciplina, ementa, formas de avaliação e, até mesmo, oferecimento de cursos de cunho pedagógico aos docentes envolvidos podem ser ações que solucionem o problema.

$\mathrm{Na}$ figura 2 sistematiza-se agrupamento de disciplinas avaliadas com algum tipo de falha ou fragilidades didático-pedagógicas.

Figura 2 -

Fragilidades na formação em áreas técnicas apresentadas por egressos em Engenharia Química da UFTM (2014-2019).

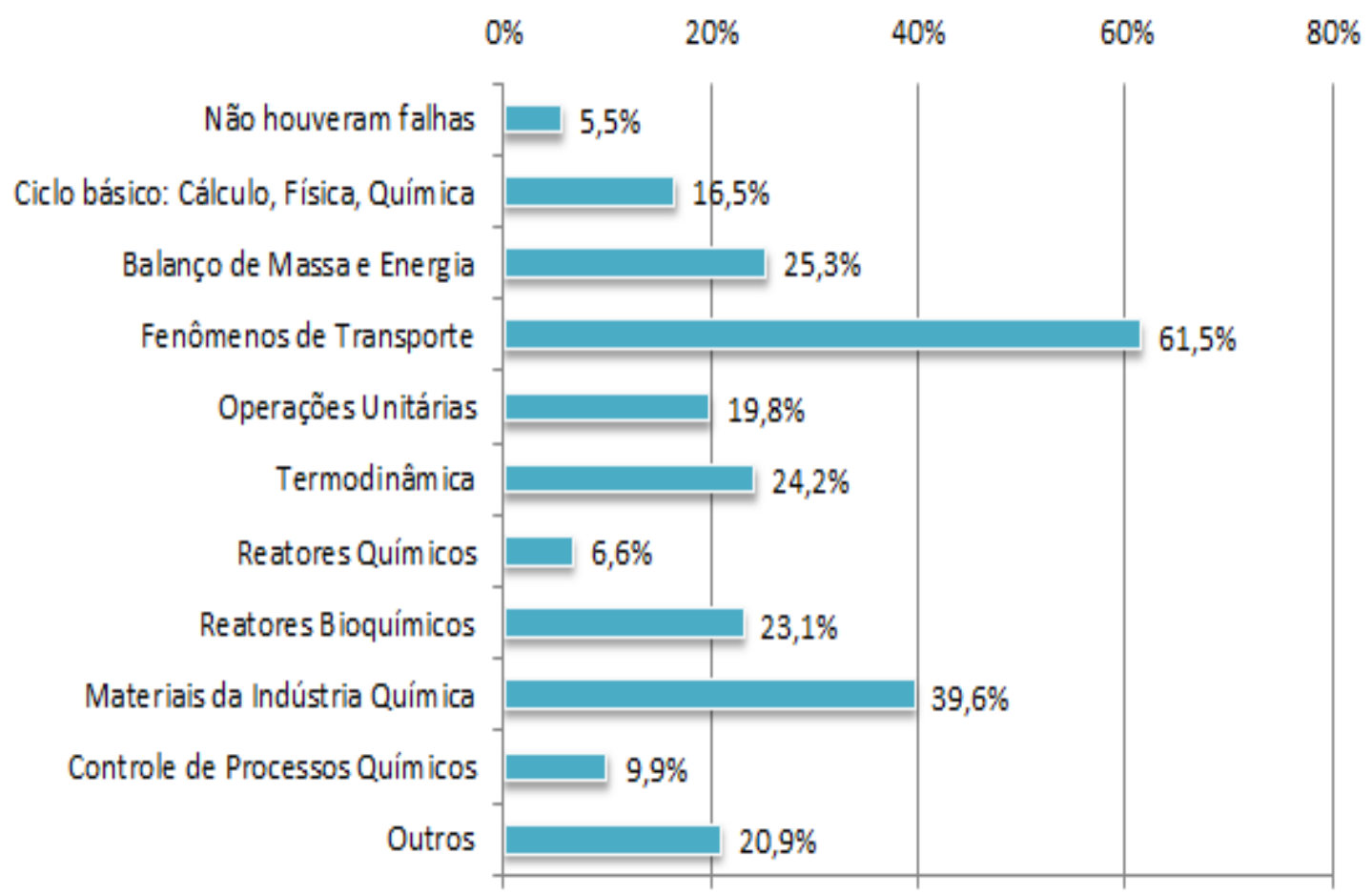

Fonte: autores (2020).

De acordo com os egressos as áreas em que menos houve problemas de formação foram Controle de Processos Químicos, com 9,9\%, e Reatores Químicos, que contou apenas com uma minoria de 6,6\%, levando em conta o nível de dificuldade da disciplina para a Engenharia Química e sua ementa extensa.

Em relação à carga horária as disciplinas do ciclo básico foram avaliadas como satisfatórias. Porém, em relação à qualidade de ensino a disciplina de Física foi a com menor índice de satisfação. A mesma avaliação foi realizada para as áreas específicas do curso como Processos Químicos, Termodinâmica, Reatores Químicos, Operações Unitárias, Fenômenos de Transporte, Engenharia Bioquímica, Controle de Processos Químicos e as disciplinas eletivas. De acordo com a avaliação dos egressos as disciplinas eletivas Processos Químicos e Fenômenos de Transporte obtiveram o índice insatisfatório para carga horária. Associadas a carga horária a qualidade do ensino também deixou a desejar nas disciplinas relacionadas a Processos Químicos e Fenômenos de Transporte, demonstrando a necessidade de uma reavaliação da ementa dessas áreas, no plano 
didático-pedagógico, didática exercida pelos professores e métodos de ensino, as quais são fundamentais para as bases de um engenheiro químico. Além disso a qualidade de ensino das disciplinas de Termodinâmica e Engenharia Bioquímica não foi completamente satisfatória, segundo os egressos.

Dentro deste contexto, foram avaliados também quesitos que contribuíram para formação dos egressos sendo os mais bem avaliados a atualização dos professores e sua titulação o relacionamento professor/aluno, existência da empresa júnior, atendimento da secretaria e acesso à coordenação do curso. Os que carecem de maior atenção e melhorias são a experiência prática dos professores, diversidade nos métodos de ensino, modernidade dos laboratórios, qualidade do restaurante universitário e oferta de extracurriculares.

Ressalta-se que a graduação em Engenharia Química da UFTM foi recentemente iniciada no ano de 2010, entretanto, a infraestrutura da universidade não foi o quesito mais citado em relação às fragilidades no ensino. Como pode-se observar mais de $70 \%$ dos alunos consideram a prática didático-pedagógica dos docentes um ponto a ser melhorado, juntamente com a ligação teoria/prática, que foi altamente citada nos dizeres, e o número de aulas práticas foi considerado baixo.

"As aulas práticas no meu período de formação, não tinha nada que agregasse conhecimento, a não ser os projetos que tínhamos que desenvolver por conta, como em DPQ10."

"Acredito que a união entre teoria e prática foi primordial. As habilidades treinadas durante a disciplina de DPQ contribui muito para aguçar minha curiosidade sobre diversos projetos. No entanto, sem a teoria aprendida antes, esta prática seria sem sentido."

"A grade curricular do curso deveria se voltar cada vez mais para aulas práticas e para inclusão de disciplinas focadas na formação profissional dos alunos.

Fazer trabalhos mais interdisciplinares já que os problemas do dia-a-dia não se limitam a uma determinada disciplina. Fazer mais estudos de caso, com mais tempo de problemas na prática. Além disso, melhorar e expandir o ensino em softwares, que são muito requisitados pelas empresas."

"A EQ-UFTM no geral é um curso bom, mas faltam visitas técnicas a indústria para o entendimento da utilidade da matéria no mercado de trabalho. Os professores deveriam buscar ter mais vivência no ambiente prático através de interação entre indústria/ universidade."

"Uma outra coisa, que eu sugiro aos Professores é testar a habilidades dos alunos não só em provas, mas no desenvolvimento de projetos e trabalhos extracurriculares (como CAEQ, TRIEQ...). Faltam "desafios" para propor resolução de problemas, nem que sejam em discussões e debates em sala de aula. Falta fazer os alunos pensarem por si mesmos, entender a linha de raciocínio deles e CORRIGIR os problemas, criticar o ponto de vista, estimular este desenvolvimento pessoal, estimular o estudo em casa e forçar atividades."

10 Desenvolvimento de Processos Químicos, disciplina do curso de Engenharia Química da UFTM.

\begin{tabular}{|l|l|l|l|l|r|} 
Regae: Rev. Gest. Aval. Educ. & Santa Maria & v. 9 & n. 18 & Pub. contínua 2020 & p. 1-16
\end{tabular} 
Esses relatos mostram a importância e a necessidade de mudanças positivas no modelo atual da organização dos cursos, reestruturação de matrizes curriculares e adaptações de metodologias de ensino e aprendizagem. Nesse contexto, a avaliação dos egressos fornece notáveis subsídios e informações para elaboração de um planejamento estratégico, a fim de uma melhoria contínua para o curso.

\section{Implicações pedagógicas}

Além dos dados, os egressos fizeram sugestões de melhoria do curso, que foram classificadas, sintetizadas como propostas de melhoria para o curso. Neste tópico são apresentadas as sínteses de oito proposições: incentivo a atividades extracurriculares; relação teoria e prática; recursos computacionais; formação humanística; incentivo ao empreendedorismo; disciplina de análise e otimização de processos químicos; leitura e interpretação de textos; maior presença em monitorias.

Incentivo a atividades extracurriculares: de acordo com os relatos dos egressos o incentivo às atividades extracurriculares deve ser constante e persistente, pois aprimoram as habilidades requeridas nas Novas Diretrizes Curriculares (Brasil, 2019), demandam do discente a resolução de problemas de diversas situações vividas pelo engenheiro no diaa-dia, além de conseguirem suprir algumas defasagens no ensino em sala de aula.

Observa-se que o curso de Engenharia Química da UFTM possui atividade extracurriculares e entidades fortes como Centro Acadêmico, Empresa Júnior, Semana Acadêmica, eventos de empreendedorismo, projetos de extensão, iniciação científica e associação atlética acadêmica. Assim, o professor deve estar atento a todas as atividades extracurriculares que ocorrem no curso, incentivar a participação dos alunos e envolver as suas disciplinas de forma interdisciplinar, a fim de promover uma conexão entre o que é estudado em sala de aula e eventos extracurriculares.

Relação teoria e prática: houve apelo pelo aumento do número de aulas práticas por parte dos egressos. Segundo os participantes a união entre teoria e prática pode ser aperfeiçoada por exemplo na disciplina de Desenvolvimento de Projetos Químicos. Esta disciplina, pertencente ao ano final do curso, visa ao desenvolvimento de projetos relacionados à Engenharia Química com conhecimentos adquiridos ao decorrer do curso, com caráter interdisciplinar, estimulando a ligação teoria/prática, trabalho em equipe e senso crítico.

De acordo com os egressos pode-se usar a integração curricular por meio de estudos temáticos em um mesmo período letivo ou anualmente. A integração curricular define o trabalho de disciplinas diferentes atuando em conjunto, compartilhando trabalhos, projetos, desafios e práticas. Para que a integração ocorra em um mesmo período letivo, é necessário que as disciplinas tenham um elo, tal como um estudo temático, definido por um tema a ser estudado para fundamentar a solução de um problema proposto. Para a realização dos projetos, anualmente, deve-se integrar vários campos do conhecimento da formação do engenheiro químico, como a disciplina de DPQ já propõe, todavia, poderiam ser escolhidos vários temas para que um maior conjunto de conhecimentos seja usado.

De acordo com os aspectos avaliados a Engenharia Química da UFTM ainda não possui parcerias com empresas locais e nacionais, o que possibilitaria a execução de projetos conjuntos, propostas de estágios e melhor visibilidade dos alunos na realidade industrial/empresarial. 
Recursos computacionais e tecnológicos: a inclusão de maior quantidade de recursos computacionais e tecnológicos em todas as disciplinas foi outro tópico destacado nesta pesquisa. Este aspecto foi abordado pelos egressos como de extrema relevância, pois como observado por Serafim (2019) com a indústria 4.0 cálculos e projetos não são mais feitos à mão e no papel, mas sim em softwares tecnológicos avançados. Segundo os egressos deve-se buscar 0 ensino de programas atualizados que possam ser devidamente utilizados nas disciplinas específicas e que sejam compatíveis com mercado de trabalho em acelerada evolução tecnológica. Outro ponto abortado foi a discrepância do estudante começar a ter contato com os sistemas operacionais específicos para Engenharia Química somente nos seus últimos períodos de permanência na universidade.

Disciplina de Análise e Otimização de Processos Químicos: de acordo com os egressos, essa é uma disciplina que aborda em sua totalidade todas as outras disciplinas envolvidas, usando todos os conceitos e fundamentos já estudados, além de estimular o uso de softwares com simuladores de processos. Segundo os egressos a abordagem que é dada não condiz com a importância da disciplina e com a necessidade do mercado.

Para eles a disciplina deveria ser abordada mais profundamente e como mais didática, pois resume, em sua totalidade, as metodologias de melhoria da indústria química. Além disso, os egressos sugerem a ampliação da carga horária para dois semestres letivos, a fim de abordar, detalhadamente, todos os equipamentos, técnicas e sistemas que são aplicados na indústria.

Formação humanística: outro tema relevante destacado pelos egressos foi a urgência da inserção da formação humanística nos cursos de Engenharia em geral, que permitam ao discente compreender melhor a realidade que o cerca, os aspectos morais, éticos e filosóficos, envolvidos na convivência em sociedade para obter uma formação cultural mais ampla.

Incentivo ao empreendedorismo: existe uma defasagem no ensino e aplicação de métodos relacionados ao empreendedorismo no curso de Engenharia Química da UFTM. Quando ensinado o empreendedorismo auxilia os estudantes a gerirem riscos, negócios e resultados, além do aspecto interdisciplinar que aflora a criatividade, que são habilidades intensamente esperadas pelo mercado de trabalho. Os métodos que melhor desenvolvem o espírito empreendedor nos alunos podem ser aplicados através de trabalho em equipe, aprendizagem baseada em problemas reais, apresentações de trabalhos, seminários e estágios.

Leitura e compreensão de textos científicos em inglês: de acordo com os egressos a leitura e compreensão de textos científicos em inglês foi relatada como falha, mesmo nos últimos níveis de formação. Assim, a cultura da leitura de textos técnicos e científicos deve ser encorajada, sugere-se uma maior quantidade de aulas de intervenção e de debates, sobre a leitura de artigos científicos, para que sejam discutidos abertamente o caráter técnico e científico, a relevância para área.

Ademais, os estudantes e professores necessitam dar atenção ao que os outros países de referência estão estudando e pesquisando e como podem elevar o padrão de ensino e pesquisa da universidade a nível internacional, além de, também, ser uma possibilidade de incentivo da leitura em inglês. 
Maior presença em monitorias: para maior presença em monitorias os egressos sugerem que 0 aluno deve entender a importância do programa de monitoria desenvolvido pela universidade e não o ver como uma obrigatoriedade ou como um meio somente para sanar dúvidas. Além disso, os docentes devem ajudar no fomento da assiduidade da monitoria.

A monitoria deve ser vista como uma forma complementar de construção do conhecimento e de formação tanto para os discentes atendidos quando para o monitor. É importante que os monitores resolvam exercícios exclusivos com os alunos presentes nas monitorias, a fim de melhorar a curiosidade e o índice de presença e permanência no programa, inclusive criando, na monitoria, um local descontraído, com a preparação de atividades lúdicas e alternativas. Como sugestão os monitores poderiam ter uma base para gravar suas aulas e disponibilizá-las para o restante dos alunos.

\section{Considerações finais}

Este estudo, na medida em que buscou a avaliação a partir da visão dos egressos do curso de Engenharia Química da Universidade Federal do Triângulo Mineiro, permitiu visualizar a configuração do curso e as possíveis necessidades dos atuais alunos e do mercado de trabalho. Identificou-se a posição do egresso no mercado de trabalho, sua percepção sobre o curso de Engenharia Química da UFTM e o impacto de sua formação em sua vida profissional e pessoal, além de sugestões e aplicabilidades viáveis, relacionadas à vida acadêmica na IES.

Mesmo não sendo a diretriz essencial, a formação generalista do engenheiro químico possibilita uma variedade de possibilidades de atuação no mercado de trabalho o que facilita a inserção deste profissional em várias áreas. Este perfil generalista pode ampliar o leque de oportunidades, o que justificaria um menor índice de ex-alunos contratados como engenheiro químico. Este fato ficou evidenciado na pesquisa pelo baixo número de egressos contratados para a área específica de formação. Porém, a maioria dos respondentes declararam-se satisfeitos com o curso e com a formação acadêmica recebida.

Em relação às disciplinas foi evidenciada uma defasagem no ensino de disciplinas fundamentais para a formação, como Fenômenos de Transporte, Balanço de Massa e Energia e Materiais da Indústria Química. As fragilidades se concentram na didática desempenhada, necessidade da aplicação do conhecimento em inovações tecnológicas e dificuldade da relação entre a realidade do mercado de trabalho e a sala de aula. Os egressos apontaram que é necessária atenção com relação à experiência prática e à vivência de mercado de trabalho. A falta de ligação teoria/prática ficou em evidência, juntamente com a falta de experiência profissional por parte dos professores, o que, possivelmente, é uma das causas desse distanciamento teórico-prático. Nesse sentido, destaca-se a necessidade de investimento na área de formação pedagógica dos docentes a fim de que sejam capazes de reavaliar suas práticas de ensino e a forma como estão mensurando a aprendizagem. Outro ponto relevante é uma maior desburocratização dos processos de parceria Universidade-Empresa a fim de ampliar o acesso dos discentes a situações reais encontradas apenas no ambiente industrial. 
Como principais observações deste trabalho destacam-se a necessidade de investimentos na formação didático-pedagógica do docente, em inovações tecnológicas para o curso e na maior relação entre o mercado com a universidade.

Espera-se que este estudo possa contribuir de forma efetiva na compreensão das necessidades do mercado de trabalho, com o intuito de que o curso reflita sobre novas estratégias de ensino-aprendizagem, formas de avaliação e organização. Além disso, esta pesquisa sugere uma maior intervenção da Universidade pela busca de parcerias públicoprivadas a fim de aumentar as possibilidades de novos laboratórios, aquisição de equipamentos e consumíveis, parcerias de pesquisa e extensão a fim de possibilitar recursos para que o docente traga a realidade para o contexto da sala de aula. Além disso, este trabalho pode ser usado como um incentivo e modelo para que outros cursos a partir da visão dos egressos levantem pontos de melhorias e ampliação das suas práticas pedagógicas.

\section{Referências}

ANGELO, Debora Mallet Pezarim; GIANESI, Irineu Gustavo Nogueira. O projeto pedagógico para as novas diretrizes curriculares de engenharia. In: OLIVEIRA, Vanderli Fava de (org.) $A$ engenharia $e$ as novas DCNs: oportunidades para formar mais e melhores engenheiros. São Paulo: Gen/LTC, 2019, p. 86-103.

BRASIL. Resolução n. 2, de 24 de abril de 2019: institui as diretrizes curriculares nacionais do curso de graduação em Engenharia. Brasília: DOU, 26 de abril de 2019, $\begin{array}{lllll}\text { Seção } & 1, & \text { p. } & 43-44 & \text { Disponível }\end{array}$ http://portal.mec.gov.br/index.php?option=com_docman\&view=download\&alias=112681 rces002-19\&category_slug=abril-2019-pdf\&Itemid=30192. Acesso em 11 mai. 2020.

FARIA, Adriana Ferreira; SOUZA JUNIOR, Antonio Claret Rodrigues de. Propostas de melhoria do projeto pedagógico através do acompanhamento dos egressos. Revista Gestão da Produção Operações e Sistemas, Bauru, n. 1, 2007, p. 33-41.

GAIA, Elizabeth Silva; GAYDECZKA, Beatriz. O contexto de criação de material instrucional para orientação do ingresso inicial na educação superior. Revista Brasileira de Ciência, Tecnologia e Inovação, Uberaba, v. 1, n. 3, 2016, p. 17-26.

GIACOMIN, Camila; SIMON, Lilian Wrzesinski; TOSTA, Kelly Cristina Benetti Tonani. Perfil e perspectivas dos egressos do curso de Administração da UFFS: um estudo realizado no Campus Chapecó/SC. Revista Gestão Universitária na América Latina GUAL, Florianópolis, 2019, p. 183-205.

IBGE. Pesquisa nacional por amostra de domicílios contínua - PNAD Contínua Trimestral. Disponível em https://sidra.ibge.gov.br/tabela/4095/. Acesso em 15 jan. 2020.

INSTITUTO DE ENGENHARIA. Mulheres são $40 \%$ dos pesquisadores do Brasil que declaram ter doutorado nas 5 maiores áreas de conhecimento, aponta levantamento. 2020. Disponível em https://www.institutodeengenharia.org.br/site/2020/02/12/mulheressao-40-dos-pesquisadores-do-brasil-que-declaram-ter-doutorado-nas-5-maiores-areas-deconhecimento-aponta-levantamento/ Acesso em 15 mar. 2020.

LOMBARDI, Maria Rosa. Perseverança e resistência: a engenharia como profissão feminina. Campinas: Unicamp, 2005. 286f. Tese (doutorado em Educação). Universidade de Campinas. 
LOUSADA, Ana Cristina Zenha; MARTINS, Gilberto de Andrade. Egressos como fonte de informação à gestão dos cursos de Ciências Contábeis. Rev. contab. finanç., São Paulo, v. 16, n. 37,2005 , p. $73-84$.

MELLO, Mario Fernando; SFALCIN, Pâmela; MACHADO, Caroline Martins; SCHMIDT, Alberto de Souza. O engenheiro químico e o mercado de trabalho: expectativas e realidade. ENGEVISTA, v. 15, n. 2, 2013, p. 187-201.

OLIVEIRA, Vanderli Fava de; PINTO, Danilo Pereira. Educação em Engenharia como área do conhecimento. CONGRESSO BRASILEIRO DE ENSINO DE ENGENHARIA, 34, 2006. Anais ... Juiz de Fora: Abenge, 2006. Disponível em http://www.abenge.org.br/cobenge/arquivos/13/artigos/12 85 357.pdf. Acesso em 11 maio 2020.

OLIVEIRA, Vanderli Fava de; ALMEIDA, Nival Nunes; CARVALHO, Dayane Maximiano de; PEREIRA, Fernando Antonio Azevedo. Um estudo sobre a expansão na formação em engenharia no Brasil. Revista de Ensino de Engenharia da Abenge, v. 32, 2013, p. $29-44$. Disponível em http://www.ufjf.br/observatorioengenharia/files/2012/01/ExpEngRevAbenge.pdf. Acesso em 11 maio 2020.

PINTO, Danilo Pereira; PORTELA, Júlio César da Silva; OLIVEIRA, Vanderli Fava de. Diretrizes Curriculares e Mudança de Foco no Curso de Engenharia. CONGRESSO BRASILEIRO DE EDUCAÇÃO EM ENGENHARIA, 31, 2003. Rio de Janeiro: Abenge, 2003. Disponível em http://www.abenge.org.br/cobenge/arquivos/16/artigos/DCS646.pdf. Acesso em 11 maio 2020.

REIS, Fábio José Garcia; COVAC, Fernando; COVAC, José Roberto. Novos instrumentos de avaliação favorecem inovação nas IES. 2018. São Paulo: Semesp, 2017. Disponível em https://www.semesp.org.br/wp-content/uploads/2018/01/Novos-instrumentos-deavaliação-favorecem-inovação-nas-IES-1.pdf . Acesso em 11 maio 2020.

RIBEIRO, Cássio Garcia; OLIVEIRA, Alanna Santos de; ZANNETTI, Maria Laura. A indústria de transformação da mesorregião do Triângulo Mineiro e Alto Paranaíba: evidências empíricas no período 2006-2015. ENCONTRO DA NACIONAL DE ECONOMIA INDUSTRIAL E INOVAÇÃO, 2, 2017. Anais ... Rio de Janeiro: UFRJ, 2017. Disponível em https://www.proceedings.blucher.com.br/article-details/a-indstria-detransformao-da-mesorregio-do-tringulo-mineiro-e-alto-paranaba-evidncias-empricas-noperodo-2006-2015-26644 Acesso em 11 maio 2020.

SERAFIM, Milena Pavan. Como será o cenário da educação superior em 2030? Avaliação, Campinas, v. 24, n. 3, 2019, p. 569-572.

VASCONCELOS, Natália Veloso Caldas de. Egressos na avaliação da qualidade de um curso: o caso da engenharia de produção da UFRN. Natal: UFRN, 2012. $175 f$. Dissertação (Mestrado em Engenharia de Produção) - Universidade Federal do Rio Grande do Norte.

VIVAS, Vinícius Henrique; SILVA, Priscila Pereira; ALVES, Luciene; MALPASS, Geoffroy Roger Pointer. Análise do perfil, motivação, satisfação e expectativas dos acadêmicos do curso de Engenharia Química da Universidade Federal do Triângulo Mineiro. In: MARAVIESK, Sabrina Passoni (org.). Estudos interdisciplinares: ciências exatas e da terra e engenharias. Ponta Grossa: Athena, 2018, v. 1, p. 180-195. 
Thais Gama Furini tem graduação em Engenharia Química pela Universidade Federal do Triângulo Mineiro.

Orcid: http://orcid.org/0000-0003-1748-8463.

Endereço: Rua Timbues, 574 - 14500-000 - Ituverava - SP - Brasil.

E-mail: thais gf@live.com.

Vinícius Henrique Vivas tem mestrado em Engenharia Química pela Universidade Federal de Minas Gerais.

Orcid: http://orcid.org/0000-0002-2172-2040.

Endereço: Rua Lazaro Severino Gomes, 55 - 38184-829 - Araxá - MG - Brasil.

E-mail: viniciusvivas@yahoo.com.br.

Beatriz Gaydeczka é professora no Programa de Mestrado Profissional em Inovação Tecnológica da Universidade Federal do Triângulo Mineiro.

Orcid: http://orcid.org/0000-0002-2604-6504.

Endereço: Avenida Randolfo Borges Júnior, 1400 - 38064-200 - Uberaba - MG Brasil.

E-mail: beatriz.gaydeczka@uftm.edu.br.

Priscila Pereira Silva é professora na Universidade Federal do Triângulo Mineiro. Orcid: http://orcid.org/0000-0002-5582-7342.

Endereço: Avenida Randolfo Borges Júnior, 1400 - 38064-200 - Uberaba - MG Brasil

E-mail: priscila.silva@uftm.edu.br.

Recebido em 12 de maio de 2020.

Aceito em 26 de agosto de 2020.

(c) (i) 